IN THE RED CROSS WORLD

\title{
SWEDISH RED CROSS SEMINAR
}

At the invitation of the Swedish Red Cross Society, Mr. J. Moreillon, Director of the ICRC Department of Principles and Law, took part in a seminar for the press organized by the Society and by the Association of Journalists of Sweden at the end of February in Stockholm.

The twenty journalists present heard a paper by Professor H. Blix, Ambassador, on the Protocols additional to the Geneva Conventions, and another by Mr. O. Stroh, General Secretary of the Swedish Red Cross, on the role of journalists in disseminating Red Cross principles and international humanitarian law.

Mr. Moreillon, in his address, gave an account of the current activities of the ICRC and, like the previous speakers, replied to a great number of questions afterwards. The journalists took part in an exercise-a marked success-which required them to imagine that they were ICRC delegates and to decide how they would act in a specific situation. They said that they were pleased, as were the leading members of the National Society who attended the seminar, to have had the opportunity thus offered to get to know more about the ICRC and the steadily increasing number of duties facing it in these times.

Also during his visit to Stockholm, Mr. Moreillon spoke to the Central Committeee of the Swedish Red Cross on the problem of political detainees as the ICRC sees it, and met several prominent personalities in the Ministry for Foreign Affairs. 